\title{
A new method to assess damage to RCMRFs from period elongation and Park-Ang damage index using IDA
}

\author{
Mehrdad Aghagholizadeh $^{1}$ - Ali Massumi
}

Received: 11 February 2016/ Accepted: 15 July 2016/Published online: 26 July 2016

(c) The Author(s) 2016. This article is published with open access at Springerlink.com

\begin{abstract}
Despite a significant progress in loading and design codes of seismic resistant structures and technology improvements in building structures, the field of civil engineering is still facing critical challenges. An example of those challenges is the assessment of the state of damage that has been imposed to a structure after earthquakes of different intensities. To determine the operability of a structure and its resistance to probable future earthquakes, quick assessment of damages and determining the operability of a structure after an earthquake are crucial. Present methods to calculate damage to structures are time consuming and do not accurately provide the rate of damage. Damage estimation is important task in the fields of structural health monitoring and decision-making. This study examines the relationship between period elongation and the Park-Ang damage index. A dynamic non-linear analysis is employed with IDARC program to calculate the amount of damage and period of the current state. This new method is shown to be a quick and accurate technique for damage assessment. It is easy to calculate the period of an existing structure and changes in the period which reflects changes in the stiffness matrix.
\end{abstract}

Keywords Damage index · Period elongation - IDARC · IDA · Park-Ang damage index

Mehrdad Aghagholizadeh

mehrdad@knights.ucf.edu

1 Department of Civil, Environmental and Construction Engineering, University of Central Florida, Orlando, FL, USA

2 Department of Civil Engineering, Kharazmi University, Tehran, Iran

\section{Introduction}

One challenge for civil engineers is to assess the amount of damage to a structure caused by moderate-to-strong earthquakes. An assessment of the type and amount of damage to a structure is required to determine its operability and resistance to aftershocks and future earthquakes. Damage estimation is important task in the fields of structural health monitoring, model updating, and decisionmaking (Aghagholizadeh and Catbas 2015; Malekzadeh 2014). Several methods to evaluate the seismic vulnerability of structures have been proposed in recent years. One method, the response-based damage index, has been critically evaluated for its applicability to seismic damage evaluation. This method uses parameters, such as base shear, stiffness, drift, rotation of an element, energy, and, in some cases, dynamic characteristics of a structure (mode shape and natural period of vibration) to calculate the state of damage using mathematical functions.

All methods can be divided into two general categories, quantitative and qualitative. In this paper, a quantitative method is used to assess the state of the damage of structures (Aghagholizadeh and Massumi 2012). This paper introduces parameters as functions to calculate and express the state of damage to a structure as a numbered value. Base shear, stiffness, drift, rotation of an element, absorbed energy by elements, and Park-Paulay damage indices were used to evaluate the degree and type of damage to a structure.

The Park-Ang index was introduced in 1985 based on the drift, absorbed energy, and yielding force of each element (Park and Ang 1985). In 1987, this method was improved using computerized methods (Nateghi Elahi and Motamedi 1998; Park and Ang 1985; Park et al. 1987a). In 1989, a damage index based on a shear-drift curve was 
developed by McCabe and Hall (1989), in which drift during and after an earthquake was used to evaluate the damage assessment of a structure. Reinhorn and Valles (1995) later introduced damage evaluation in the inelastic response of structures.

In this paper, a relationship is demonstrated between period elongation in the first three modes of building seismic response and the Park-Ang damage index using non-linear incremental dynamic analysis (IDA), and a mathematical relation between period elongation and damage is proposed. This new method provides a quick and easy method of assessing the state of damage to a structure.

Softening of a structure can be assessed by monitoring the relationship between period elongation and the damage index. Cracks or plastic hinges along the elements change their stiffness, which affects the stiffness matrix of the structure. This, in turn, elongates the period. This study is based on the Park-Ang damage index, because it incorporates dissipating energy and deformation of the elements into the assessment. This index is expressed as a function of maximum deformation, yielding strength of an element, and absorbed hysteretic energy through the loading process:

DI $=\frac{\delta_{\mathrm{m}}}{\delta_{\mathrm{u}}}+\frac{\beta}{\delta_{\mathrm{u}} P_{\mathrm{y}}} \int \mathrm{d} E_{\mathrm{h}}$

where DI is the damage index, $\int \mathrm{d} E_{\mathrm{h}}$ is the hysteretic energy absorbed by the element during the response history, $\delta_{\mathrm{m}}$ is the maximum experienced deformation, $P_{\mathrm{y}}$ is the yield strength of the element, $\delta_{\mathrm{u}}$ is the ultimate deformation for an element, and $\beta$ is the mode constant, which is recommended to equal 0.1 for nominal strength deterioration (Park et al. 1987b).

The Park-Ang damage index is the most appropriate index for concrete structures, because it considers a variety of rupture states. Table 1 shows the calibrations for the Park-Ang damage index (Park et al. 1987b). Ultimate deformation for each element, story, and the whole structure is required to calculate the Park-Ang damage index for a structure. Since, in IDARC, inelastic behavior of reinforced concrete is confined to plastic zones (Park et al. 1987b), Eq. (1) can be revised as:

$$
\begin{aligned}
& \mathrm{DI}=\frac{\theta_{\mathrm{m}}-\theta_{\mathrm{r}}}{\theta_{\mathrm{u}}-\theta_{\mathrm{r}}}+\frac{\beta}{M_{\mathrm{y}} \theta_{\mathrm{u}}} E_{\mathrm{h}} \\
& \mathrm{DI}_{\text {story }}=\sum\left(\lambda_{\mathrm{i}}\right)_{\text {component }}\left(\mathrm{DI}_{\mathrm{i}}\right)_{\text {component }} ; \\
& \left(\lambda_{\mathrm{i}}\right)_{\text {component }}=\left(\frac{E_{\mathrm{i}}}{\sum E_{\mathrm{i}}}\right)_{\text {component }} \\
& \mathrm{DI}_{\text {overall }}=\sum\left(\lambda_{\mathrm{i}}\right)_{\text {story }}\left(\mathrm{DI}_{\mathrm{i}}\right)_{\text {story }} ; \\
& \left(\lambda_{\mathrm{i}}\right)_{\text {story }}=\left(\frac{E_{\mathrm{i}}}{\sum E_{\mathrm{i}}}\right)_{\text {story }}
\end{aligned}
$$

where $\theta_{\mathrm{m}}$ is the maximum rotation during the loading process; $E_{\mathrm{h}}$ is the consumed energy in the section; $\theta_{\mathrm{u}}$ is the ultimate rotation capacity of the section; $\theta_{\mathrm{r}}$ is the recoverable rotation through unloading; $M_{\mathrm{y}}$ is the yield moment; $E_{\mathrm{i}}$ is the total absorbed energy in an element or a story; and $\lambda_{\mathrm{i}}$ is the energy weighting factor. By calculating the damage index for each element, the damage indices for each story and the whole building can be obtained.

\section{Models}

\section{Software}

IDA was used to implement the proposed method using IDARC (version 7.0) (Valles and Reinhorn 2010). IDARC reads time-history inputs and gives outputs at each step, which is important for IDA. IDARC can identify the location of the plastic hinges, calculate the capacity of the elements, and implement spreading-plasticity.

A 2D model of the structure was used for the proposed method. In general, bending, shear, and axial deflections are considered in a beam and column model. For IDARC, column elements are modeled considering macro models with inelastic flexural deformations, and elastic shear and axial deformations. Beam elements are modeled using a non-linear flexural stiffness model with linear elastic shear deformations. A significant feature of IDARC to implement inelastic behavior in the macro model is to apply a distributed plasticity model with a flexibility matrix approach instead of the hinge model developed for steel

Table 1 Overall damage index description

\begin{tabular}{llll}
\hline $\begin{array}{l}\text { Descriptive damage } \\
\text { state }\end{array}$ & $\begin{array}{l}\text { Damage index } \\
\text { quantity }\end{array}$ & $\begin{array}{l}\text { State of building } \\
\text { operability }\end{array}$ & Physical state \\
\hline Collapse & More than 1.0 & Loss of building & Partial or total collapse of building \\
Severe & Between $0.4-1.0$ & Not repairable & Extensive crashing of concrete; disclosure of buckled reinforcement \\
Moderate & Less than 0.4 & Repairable & Extensive large cracks; spall of concrete in weaker elements \\
Minor & - & - & Minor cracks; partial crushing of concrete in columns \\
Slight & - & - & Sporadic occurrence of cracking \\
\hline
\end{tabular}


Fig. 1 Test setup and loading system

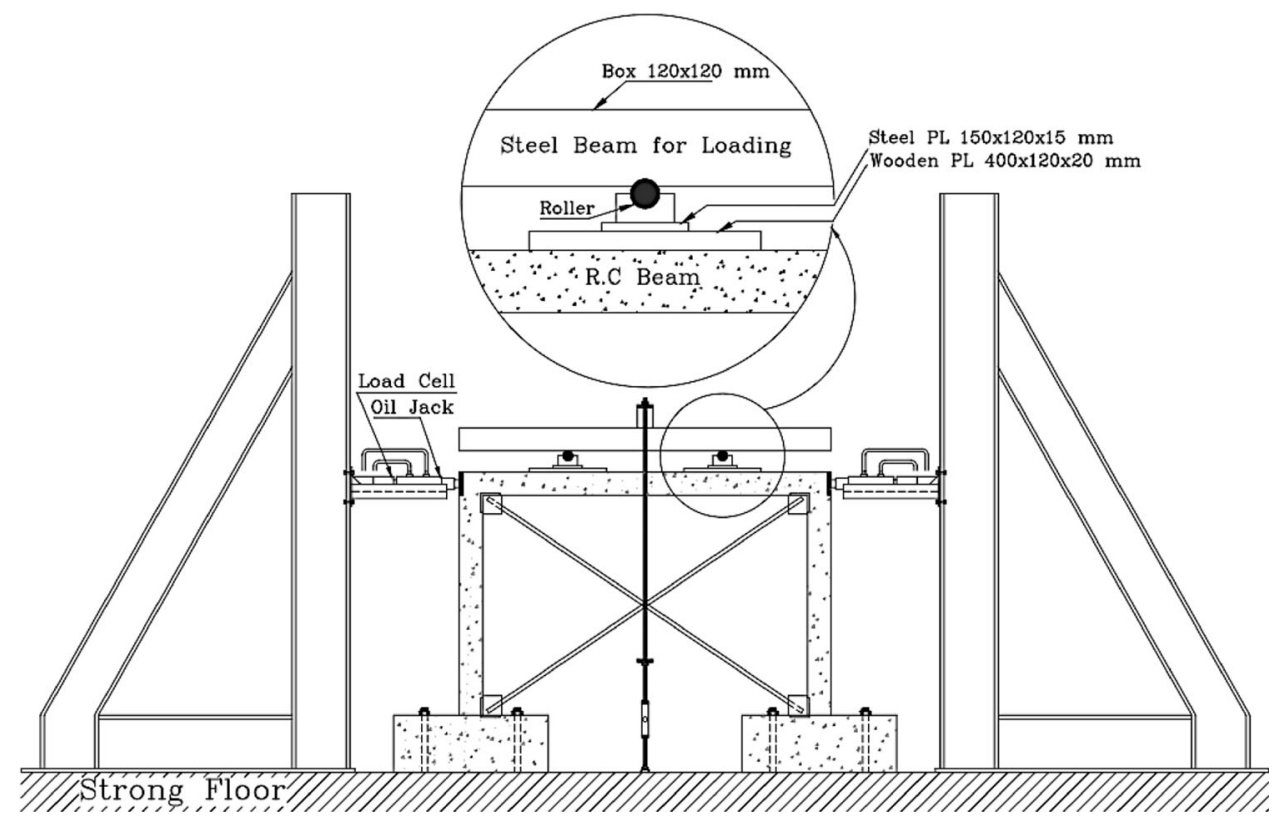

frames. The hinge model is not suitable for reinforced concrete elements, since the inelastic deformation is distributed along the members rather than being concentrated at critical sections (Park et al. 1987b). For the sake of compatibility with other programs and to model plastic characteristics, a concentrated plasticity model was also developed by IDARC.

In IDARC, moments and rotations in two sides of an element are calculated as shown in Eqs. (5) and (6), where $M_{\mathrm{A}}^{\prime}, M_{\mathrm{B}}^{\prime}, \theta_{\mathrm{A}}^{\prime}$, and $\theta_{\mathrm{B}}^{\prime}$ are moments and rotations at both ends of the beams; $\left[K^{\prime}\right]$ is the stiffness matrix of the elements, in which shear and bending stiffness are considered and calculated with spreading-plasticity; $\mathrm{EI}_{0}$ is the elastic rotational stiffness; $\mathrm{EI}_{\mathrm{A}}$ and $\mathrm{EI}_{\mathrm{B}}$ are the rotational stiffness at both ends; $\mathrm{GA}_{\mathrm{g}}$ is the shear stiffness; and $L$ is the length of the element.

$$
\begin{aligned}
& \left\{\begin{array}{l}
M_{\mathrm{A}}^{\prime} \\
M_{\mathrm{B}}^{\prime}
\end{array}\right\}=\left[K^{\prime}\right]\left\{\begin{array}{l}
\theta_{\mathrm{A}}^{\prime} \\
\theta_{\mathrm{B}}^{\prime}
\end{array}\right\} \\
& {\left[K^{\prime}\right]=\left[\begin{array}{ll}
k_{\mathrm{AA}} & k_{\mathrm{AB}} \\
k_{\mathrm{BA}} & k_{\mathrm{BB}}
\end{array}\right] .}
\end{aligned}
$$

\section{Confirmation of analysis and hysteretic model}

In analytical modeling, the input hysteretic behavior of elements plays an essential role in the overall seismic behavior of structures. If the hysteretic behavior is incorrect, the results of analytical modeling will not be practical. It is critical to calibrate the analysis using experimental data. It is critical to calibrate the analysis with experimental extracted data. Thus, a comparison

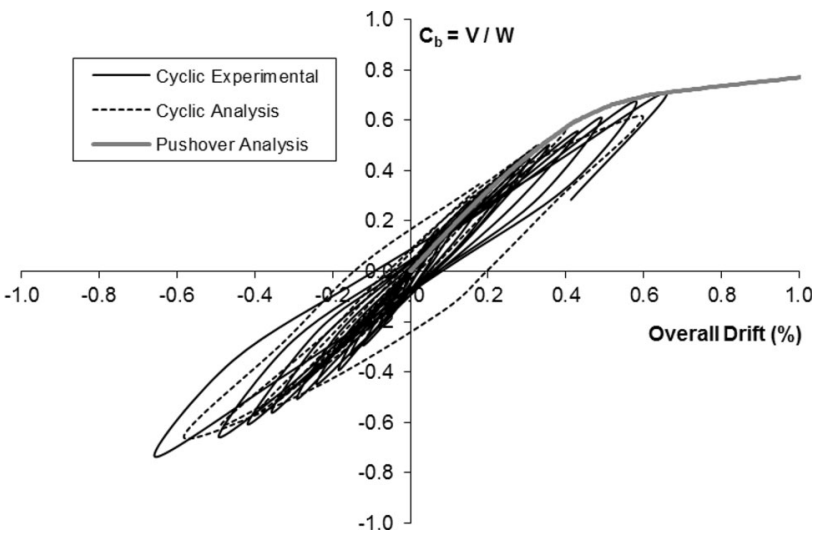

Fig. 2 Experimental and analytical data

between analytical and experimental data has been done (Massumi 2004).

The test compared analytical and experimental data on a one-story and one-bay reinforced concrete (RC) frame. The loading consisted of cyclic lateral and constant vertical loads (Fig. 1). Figure 2 shows the base shear ratio $\left(C_{\mathrm{b}}\right.$, ratio of base shear to effective weight) versus total percentage of drift for the roof. Assumptions of the material modeling are defined, so that the best calibration using the experimental data was achieved. These parameters were used in material modeling of the frames.

A multi-linear hysteretic model was chosen for the beams and columns in the present research. These assumptions are compatible with data extracted in laboratory testing (Table 2), which reflect the actual seismic behavior of a structure (Massumi 1997). 


\section{Earthquake time histories}

Seven characteristically identical earthquake records were selected. These earthquakes were assumed to occur in type B soil and had magnitudes of between 6.00 and 7.25 on the Richter scale with strike slip fault mechanisms (Figs. 3, 4, 5, 6, 7, 8, 9). Also information regarding to earthquake time histories are provided in Table 3.

Table 2 Hysteretic parameters considering laboratory results

\begin{tabular}{llll}
\hline $\begin{array}{l}\text { Stiffness } \\
\text { degradation } \\
\text { parameter }(\alpha)\end{array}$ & $\begin{array}{l}\text { Ductility-based } \\
\text { strength decay } \\
\text { parameter }\left(\beta_{1}\right)\end{array}$ & $\begin{array}{l}\text { Hysteretic energy- } \\
\text { based strength } \\
\text { decay parameter } \\
\left(\beta_{2}\right)\end{array}$ & $\begin{array}{l}\text { Slip } \\
\text { Parameter } \\
(\gamma)\end{array}$ \\
\hline 2 & 0.1 & 0.1 & 1 \\
\hline
\end{tabular}

\section{Theoretical models and analysis}

This study chose four reinforced concrete moment-resistant frames having 2, 4, 6, and 10 stories to represent low- and mid-rise frame structures. The frames were compatible with the Iranian Code of Practice for Seismic Resistant Design of Buildings (3rd edition) (Building and Housing Research Center 2005) and Part 9 of the Iranian National Building Code (Ministry of Housing and Urban Development 2005). Figure 10 shows elevated views of the four frames, each having four bays. All spans of the frames were $4 \mathrm{~m}$ in width and $3 \mathrm{~m}$ in height.

IDARC can identify the location of the plastic hinges by considering the capacity of the elements and can implement spreading-plasticity. Since this study was based on the IDA method, each earthquake history was employed using eight or more steps. The damage index and the

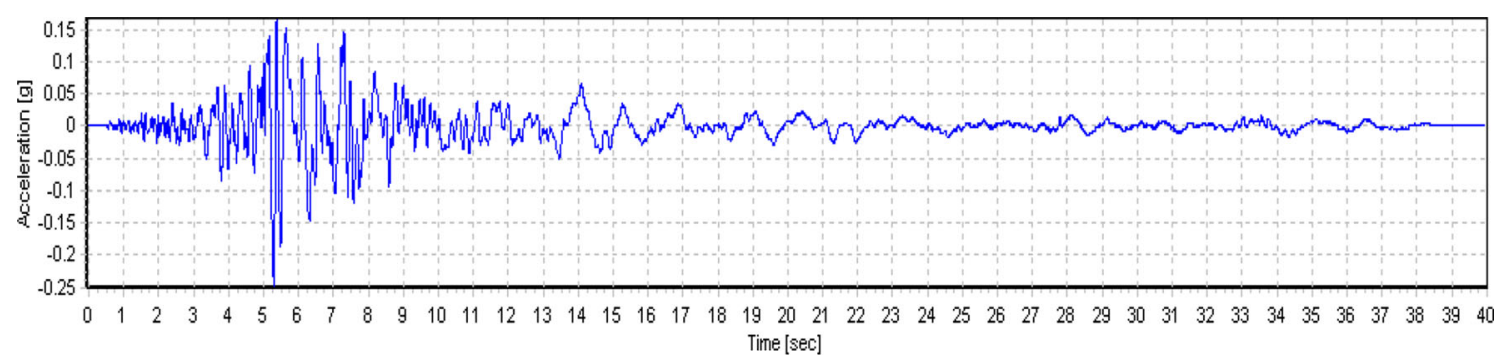

Fig. 3 Chalfant Valley earthquake record, CA, USA 1986

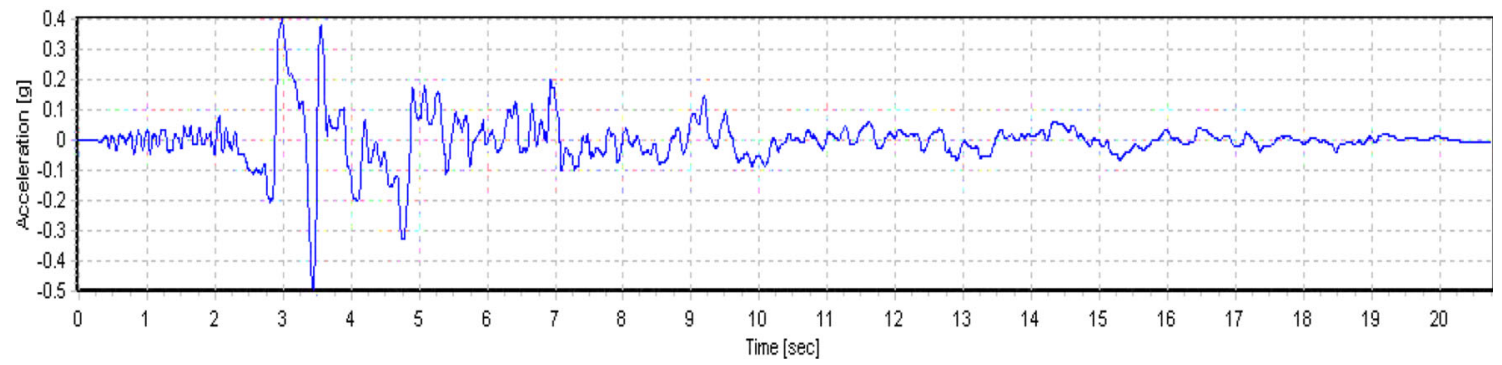

Fig. 4 Erzincan earthquake record, Erzincan, Turkey 1992

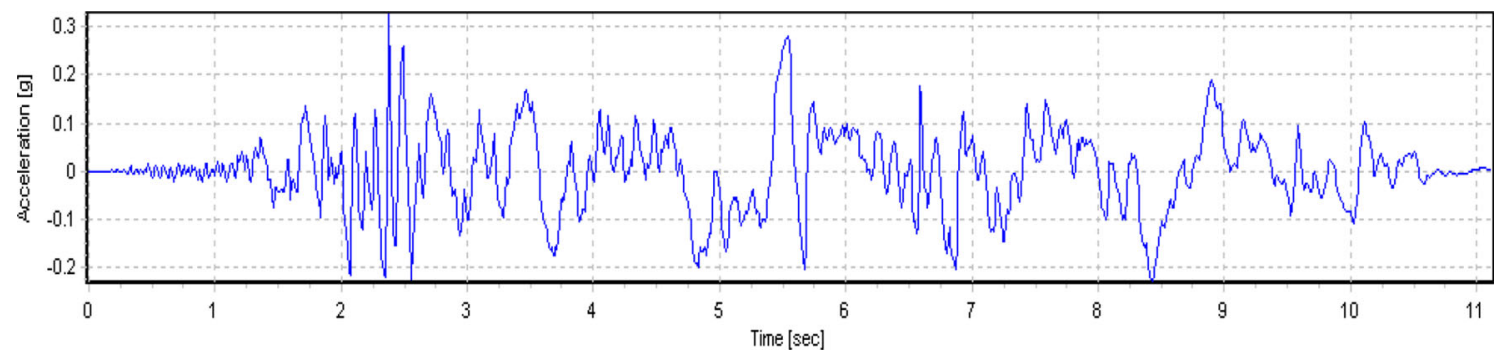

Fig. 5 Imperial Valley earthquake record, CA, USA 1979 


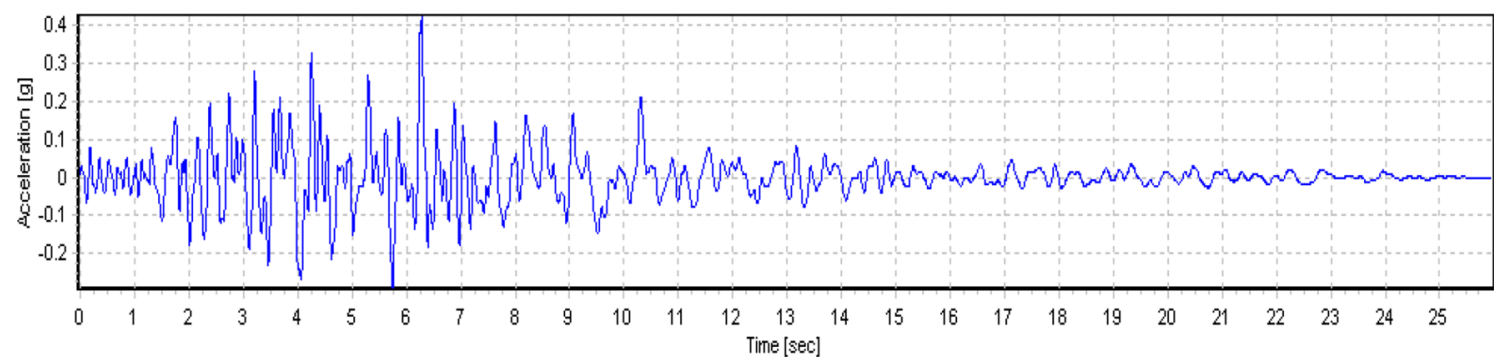

Fig. 6 Managua earthquake record, Managua, Nicaragua 1972

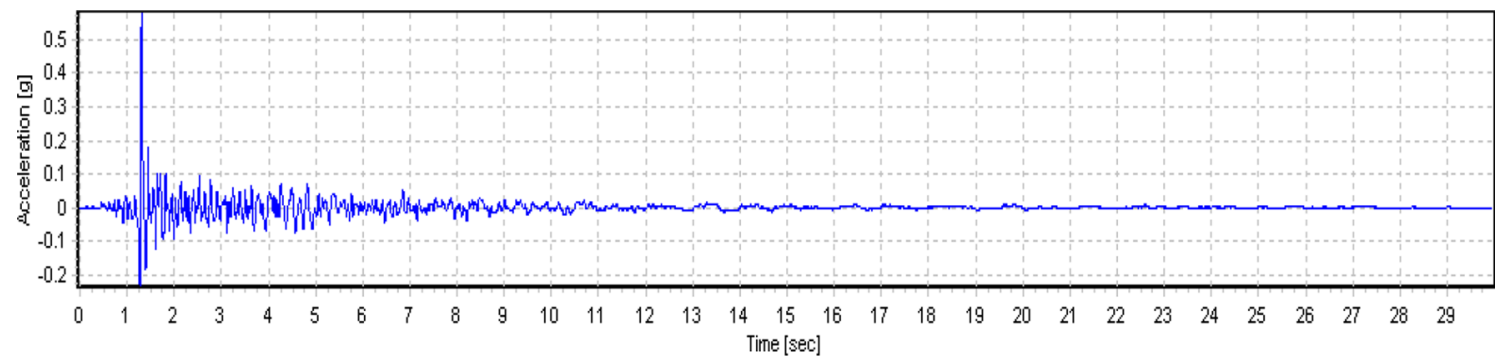

Fig. 7 Morgan Hill earthquake record, CA, USA 1984

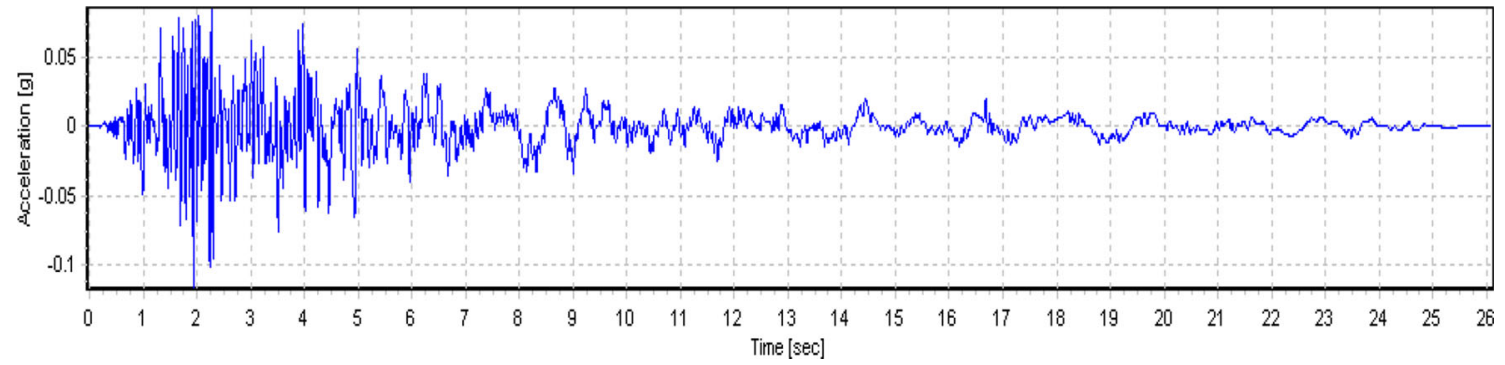

Fig. 8 Parkfield earthquake record, CA, USA 1966

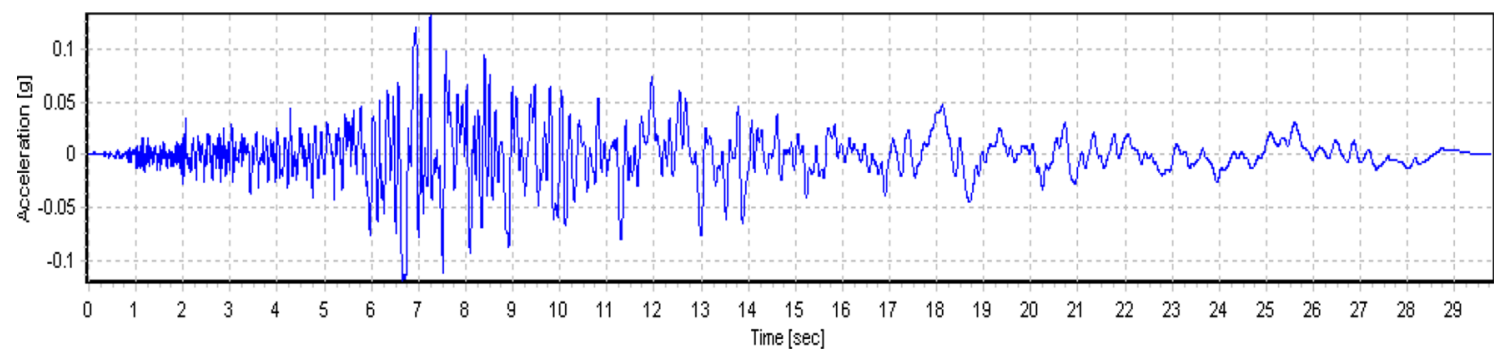

Fig. 9 Superstition Hills earthquake record, CA, USA 1987

Table 3 Characteristics of selected earthquakes

\begin{tabular}{lllllr}
\hline Earthquake & Fault mechanism & Magnitude (richter) & PGA $(\mathrm{g})$ & PGV $(\mathrm{cm} \mathrm{s})$ & PGD $(\mathrm{cm})$ \\
\hline Parkfield & Strike-slip & 6.19 & 0.3588 & 23.5829 & 4.0155 \\
Managua-Nicaragua & Strike-slip & 6.24 & 0.4183 & 26.6577 & 1966 \\
Imperial valley & Strike-slip & 6.53 & 0.3188 & 30.0354 & 6.5459 \\
Morgan Hill & Strike-slip & 6.19 & 0.1608 & 8.1744 & 6.6960 \\
Chalfant Valley & Strike-slip & 6.19 & 0.2164 & 20.0414 & 1.5218 \\
Superstition Hills & Strike-slip & 6.22 & 0.1255 & 12.2078 & 6.8207 \\
Erzincan-Turkey & Strike-slip & 6.69 & 0.4518 & 65.7330 & 6.0563 \\
\hline
\end{tabular}



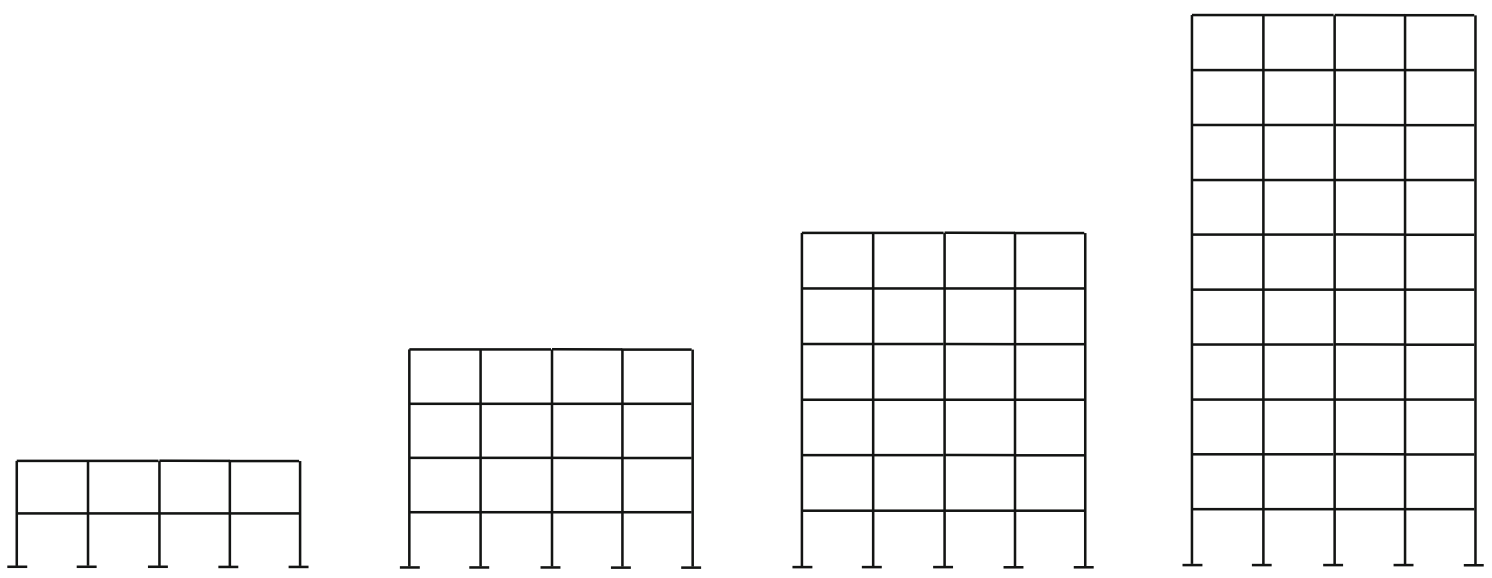

Fig. 10 Schematic representation of the frames selected

Fig. 11 Two-Story Frame period elongations vs. damage index for first two modes

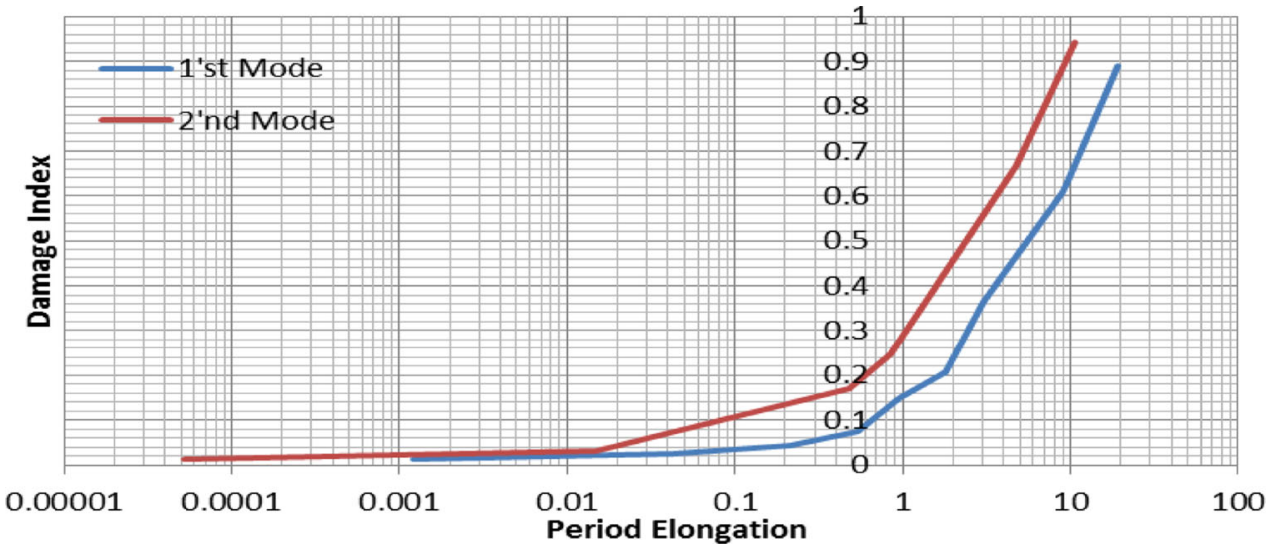

Fig. 12 Four-Story Frame period elongations vs. damage index for first three modes

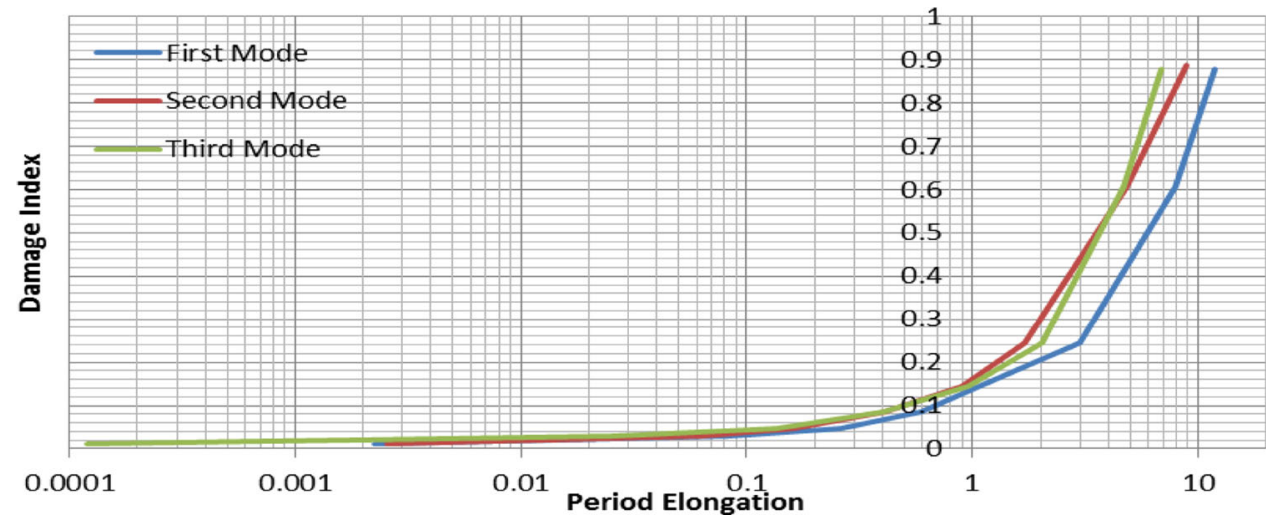

Results

periods of the first three modal periods were recorded at each step. Period elongation was then calculated using the following equation, where $T_{\text {elastic }}$ is the period before damage and $T_{\text {plastic }}$ is period of the latest damage state (Massumi and Moshtagh 2013).

Period elongation $=\frac{T_{\text {plastic }}-T_{\text {elastic }}}{T_{\text {elastic }}}$.
The results of the analysis are shown in Figs. 11, 12, 13, and 14. The results show that all three modes are elongated at each step and follow the same trend. The mean results for the average period elongations for the first three modes are shown in Figs. 15, 16, and 17. In these figures, all the modes show the same trend for change and when the 
Fig. 13 Six-Story Frame period elongations vs. damage index for first three modes

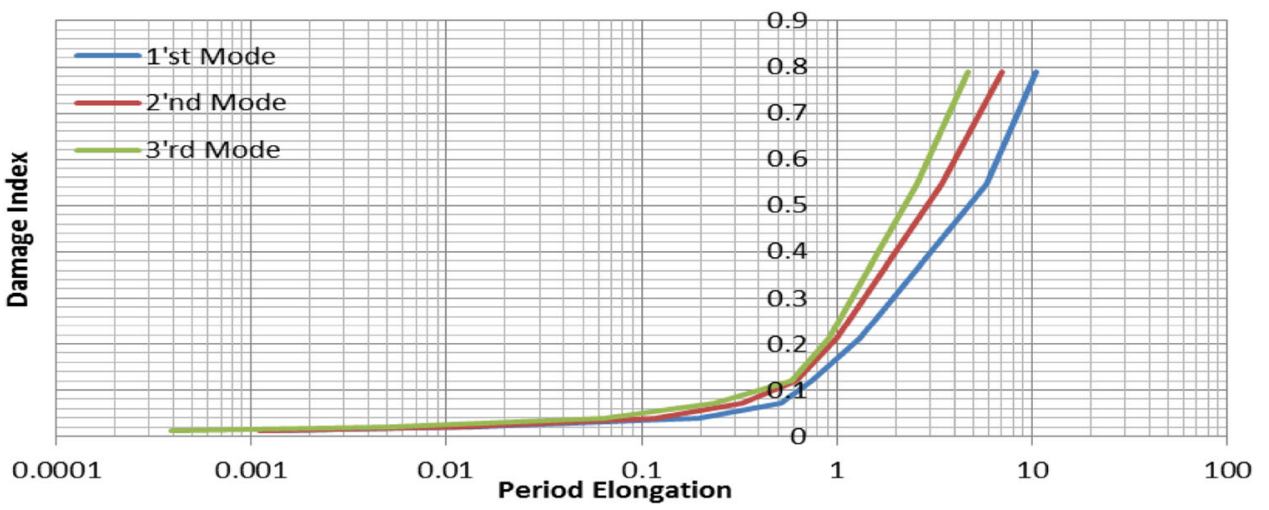

Fig. 14 Ten-Story Frame period elongations vs. damage index for first three modes

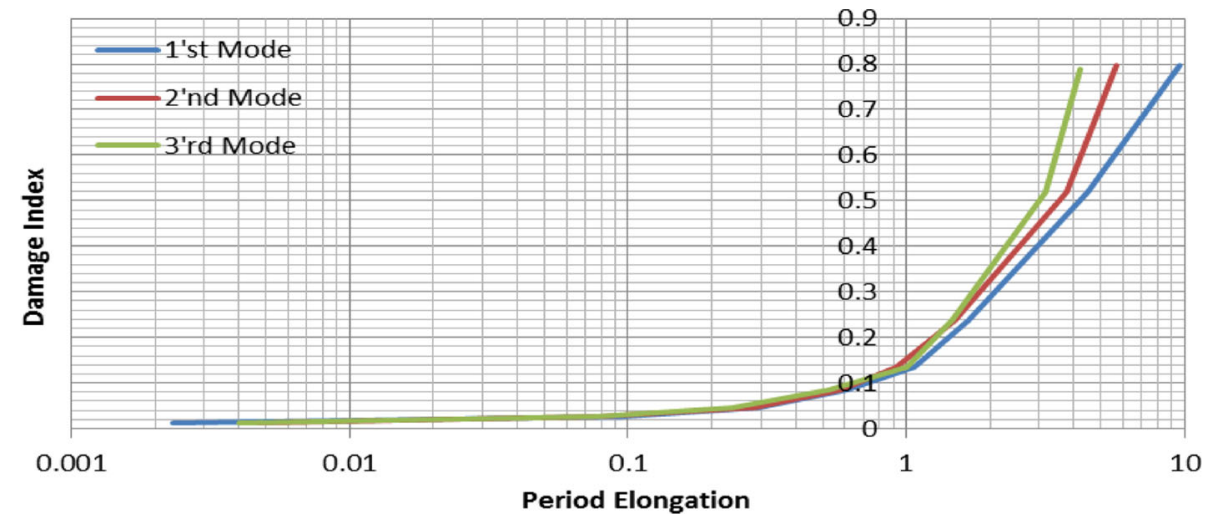

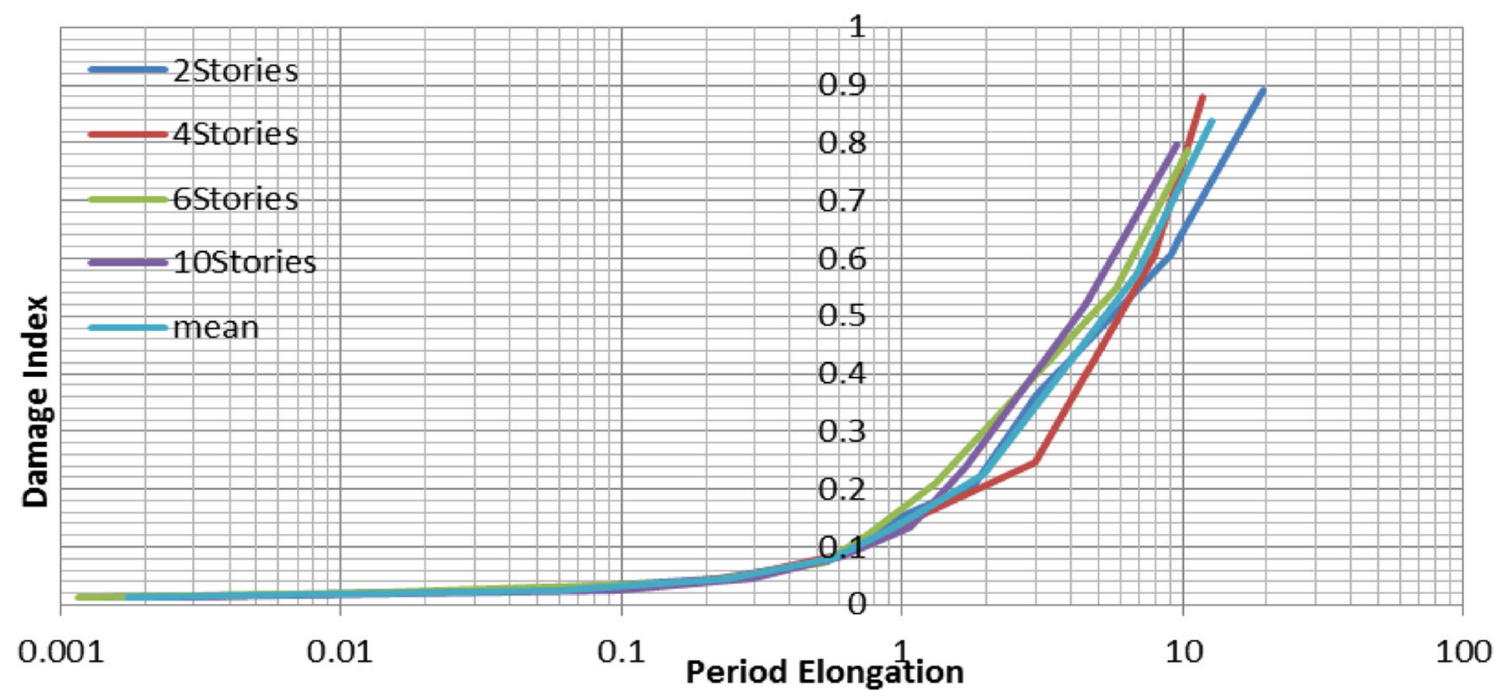

Fig. 15 First-Mode period elongations vs. damage index comparison between different frame heights

damage is around 0.15 , the period elongated to twice that of the elastic period.

\section{Identification of damage trend}

The figures show that, in the first mode, after the period elongated to about 4.8 times that of the elastic period, the
Park-Ang damage index was less than 0.4. At this value, a structure experiences repairable damage, such as extensive large cracking and spalling of concrete in the weaker elements. In the second mode, the period elongated to about 3.2 times that of the elastic period and the damage index was less than 0.4 . For the third mode, the period elongated to about 2.3 times that of the elastic period. As peak ground 


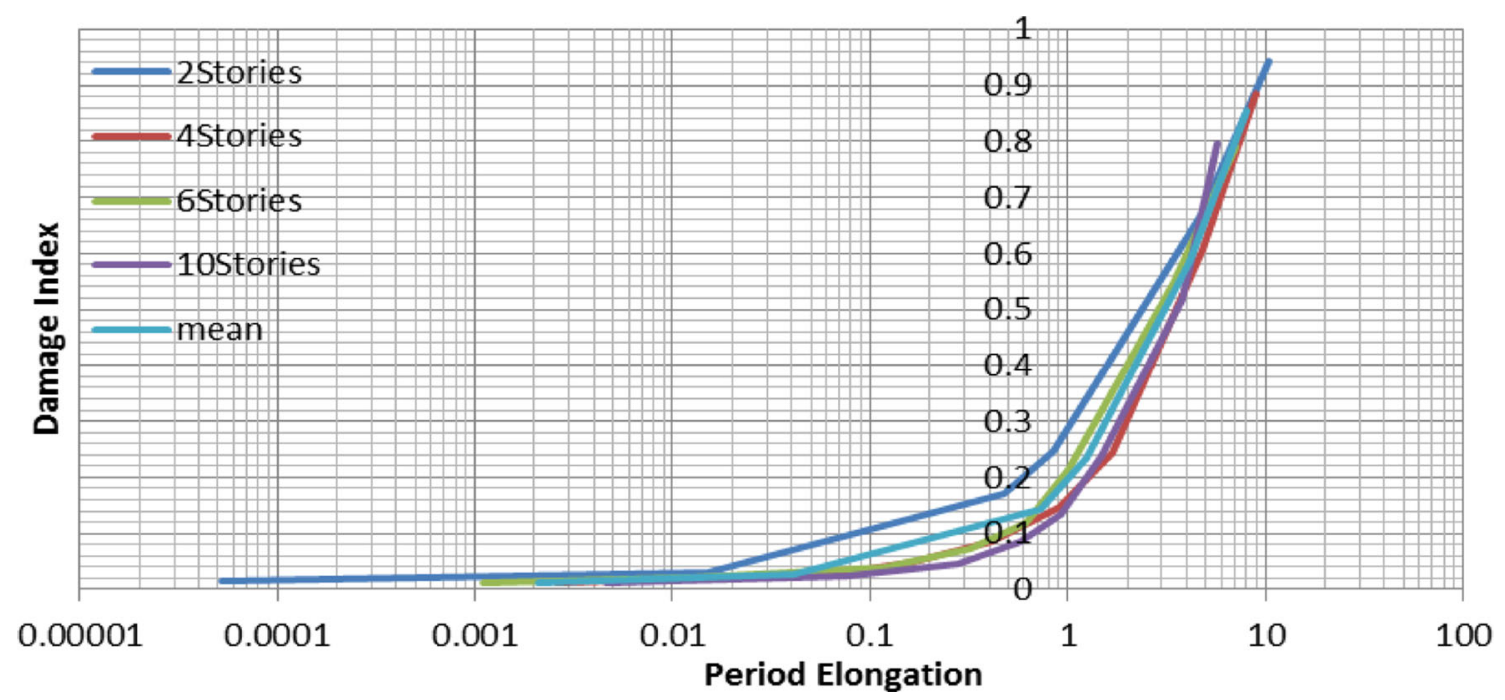

Fig. 16 Second-Mode period elongations vs. damage index comparison between different frame heights

Fig. 17 Third-Mode period elongations vs. damage index comparison between different frame heights

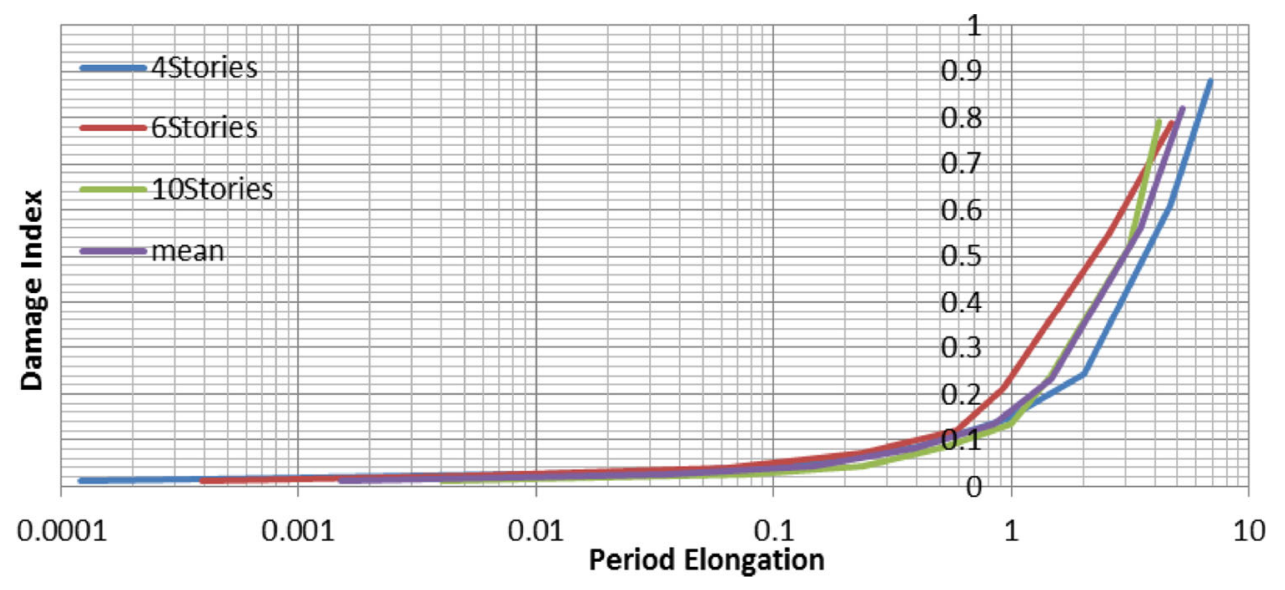

acceleration (PGA) increased, the damage index increased and damage reached a stage that was irreparable.

\section{Proposed damage pattern}

In Fig. 18, the means of period elongation versus damage index of all frames are shown for the first three modes. A curve from the extracted data set can be fitted for each mode and a mathematical relation can be proposed that makes a logical connection between period elongation and the ParkAng damage index (Figs. 19, 20, 21). A cubic polynomial was used for first and third modes and a quadratic polynomial for the second mode to decrease error. It should be noted that the curve equations are reliable when the starting point of the curve is considered to be $(0,0)$. The equations of the fitted curves for the first three modes are:

First mode: $D I=0.00032 \delta^{3}-0.0092 \delta^{2}+0.13 \delta+0.11$
Second mode: $D I=-0.009 \delta^{2}+0.18 \delta+0.014$

Third mode: $D I=-0.0014 \delta^{3}+0.01 \delta^{2}+0.14 \delta+0.015$

where $\delta$ is period elongation and DI is the damage index. The fitted curves confirm that all three modes follow the same trend. The differences between the curves and analytical values are less than $10 \%$. This error is derived from assumptions made in the curve-fitting process and from round-off error in the analytical phase.

\section{Conclusion}

The seismic behavior of a structure correlates with all of its elements and the configuration of the structure. Computation of the stiffness matrix of a structure helps define its damage state. Because obtaining the stiffness matrix of a 


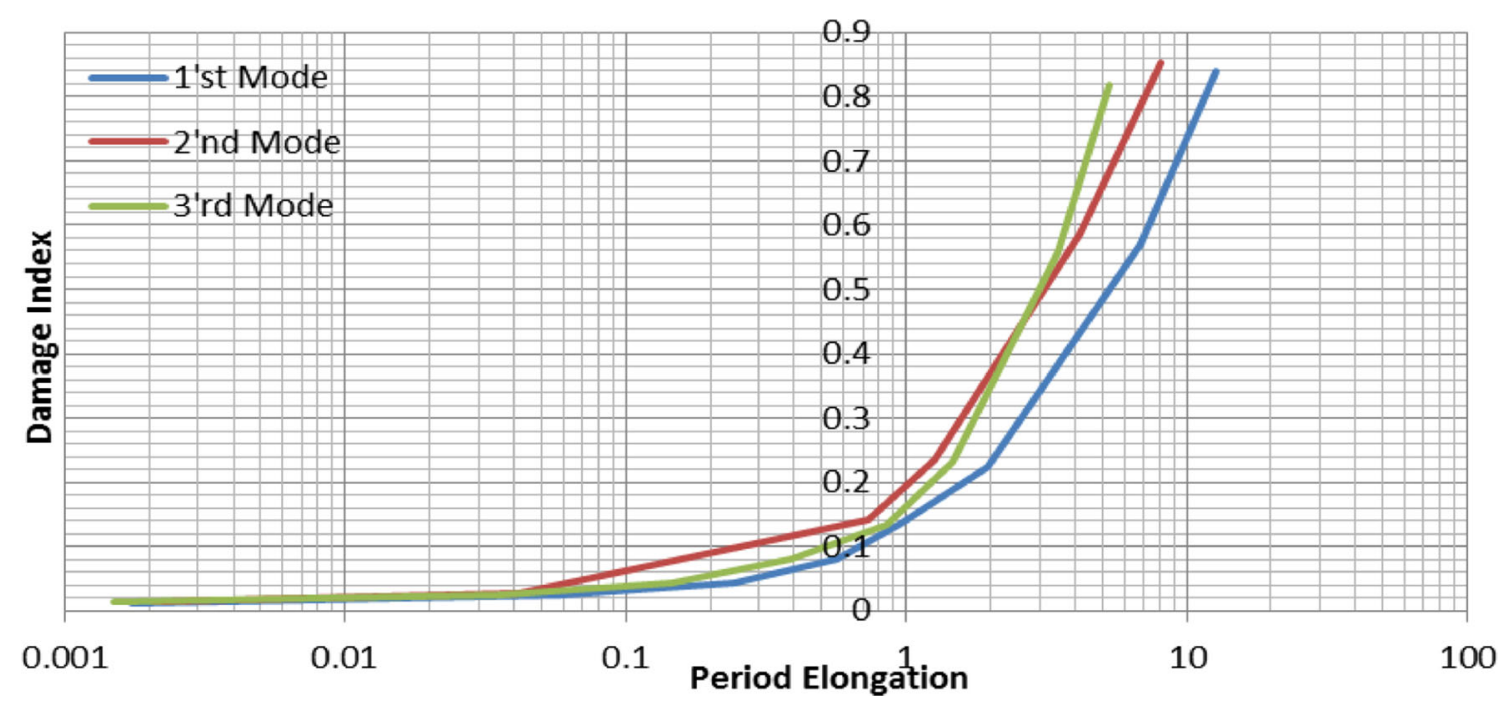

Fig. 18 Means of period elongations vs. damage index comparison for all frames in first three modes

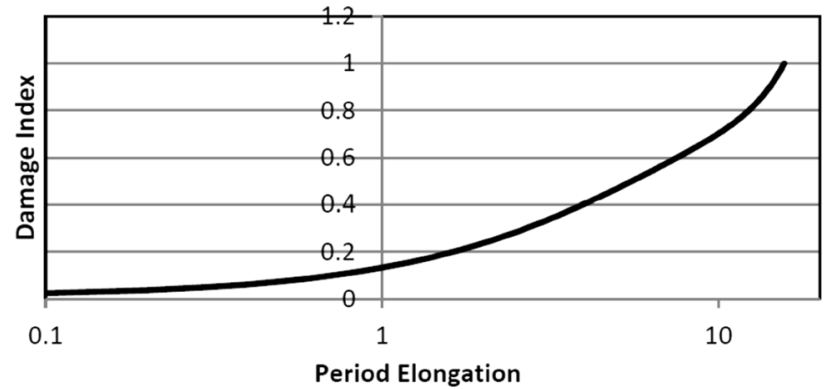

Fig. 19 First-Mode period elongations vs. damage index proposed relation

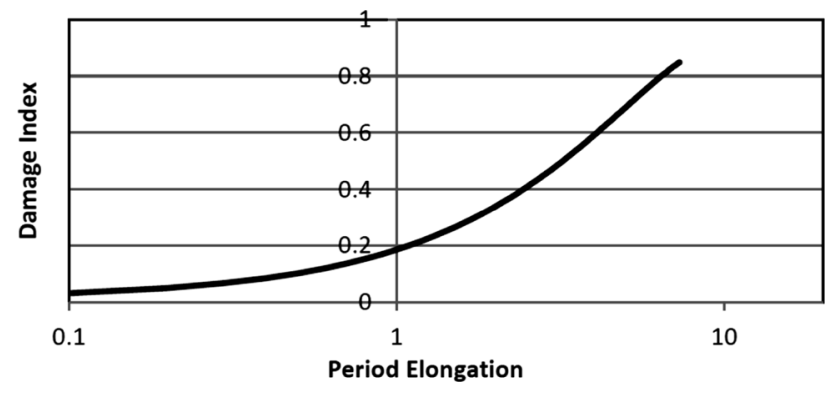

Fig. 20 Second-Mode period elongations vs. damage index proposed relation

structure is difficult and time consuming, this study proposed utilizing period elongation, which is an easy and cost-effective way to acquire a structure period. An accurate assessment of the damage state of structures using changes in the fundamental, second, and third periods was achieved in this study. The dissipating energy and deformation of an element were also considered. The Park-Ang damage index was used, because it considers a variety of rupture states.

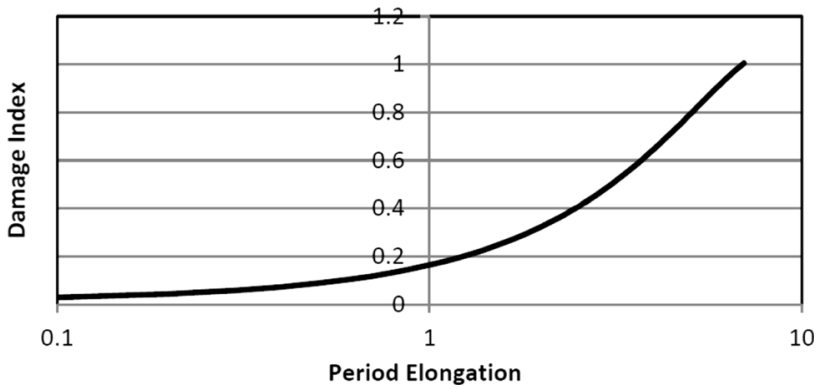

Fig. 21 Third-Mode period elongations vs. damage index proposed relation

The results showed that all three first modal periods followed the same trend, where period elongation was about 4.8. The Park-Ang damage index for the first mode was calculated to be less than 0.4 , which generally causes repairable damage to a structure. In the second mode, the period elongated to about 3.2 times that of the elastic period and the damage index was also smaller than 0.4 . For the third mode, period elongation is about 2.3 times that of the elastic period. As PGA increased in this analysis, the damage index increased and damage reached the irreparable stage.

Open Access This article is distributed under the terms of the Creative Commons Attribution 4.0 International License (http://creative commons.org/licenses/by/4.0/), which permits unrestricted use, distribution, and reproduction in any medium, provided you give appropriate credit to the original author(s) and the source, provide a link to the Creative Commons license, and indicate if changes were made.

\section{References}

Aghagholizadeh M, Catbas FN (2015) A review of model updating methods for civil infrastructure systems. In: Kruis J, 
Tsompanakis Y, Topping BHV (Eds) Computational techniques for civil and structural engineering. Saxe-Coburg Publications, Stirlingshire, Chapter 4, pp 83-99. doi:10.4203/csets.38.4

Aghagholizadeh M, Massumi A (2012) Relation between dynamic characteristics and damage index of RC-mrfs using non-linear incremental dynamic analyses. Proc. of the 15th World Conference on Earthquake Engineering, Lisbon, Portugal, Reference code 0757

Building and Housing Research Center (BHRC) (2005) Iranian Code of Practice for Seismic Resistant Design of Buildings. Standard No.2800-05, 3rd edn. Building and Housing Research Center, Tehran (in Persian)

Malekzadeh S (2014) Structural health monitoring using novel sensing technologies and data analysis methods. University of Central Florida

Massumi A (1997) "Experimental study on behavior of RC frames strengthened by steel bracings (under lateral loads)," MSc Thesis, Tarbiat Modares University, Tehran, Iran

Massumi A (2004) Estimation of response modification factors for RC-MRF structures, emphasizing on the effect of over strength and redundancy. PhD Thesis, Civil Engineering Dept., Tarbiat Modares University, Tehran, Iran

Massumi A, Moshtagh E (2013) A new damage index for rc buildings based on variations of nonlinear fundamental period. Struct Des Tall Spec Build 22(1):50-61
McCabe SL, Hall WJ (1989) Assessment of seismic structural damage. J Struct Eng ASCE 115(9):2166-2183

Ministry of Housing and Urban Development (2005) Iranian National Building Codes (Part 9: Design and Construction of Reinforced Concrete Buildings). Ministry of Housing and Urban Development, Tehran (in Persian)

Nateghi Elahi F, Motamedi M (1998) Quantitative estimation of seismic damage on concrete structures with non-linear dynamic analysis. International Institute of Earthquake Engineering and Seismology, Tehran

Park YJ, Ang AH-S (1985) Mechanistic seismic damage model for reinforced concrete. J Struct Div ASCE 111(4):722-739

Park YJ, Ang AH-S, Wen YK (1987a) Damage-limiting aseismic design of buildings. Earthq Spectra 3(1):1-26

Park YJ, Reinhorn AM, Kunnath SK (1987b) IDARC: inelastic damage analysis of reinforced concrete frame-shear-wall structures. Technical Report NCEER-87-0008, State University of New York at Buffalo

Reinhorn AM, Valles RE (1995) Damage evaluation in inelastic response of structures: a deterministic approach. Report No. NCEER-95, National Center for Earthquake Engineering Research, State University of New York at Buffalo

Valles RE, Reinhorn AM (2010) IDARC-2D Version 7.0, Inelastic Damage Analysis of Reinforced Concrete Structures. http://civil. eng.buffalo.edu/idarc2d50/ 